\title{
Melhoria contínua aplicada ao processo de abastecimento de água potável
}

\section{Continuous improvement applied to potable water supply process}

\author{
1 Byanca Porto de Lima byanca_porto@yahoo.com.br \\ 1 Sérgio Ricardo Bastos de Mello \\ 2 Paloma Medeiros de Souza \\ 2 Rafaela de Souza Lencastre
}

1 Docente do Centro Universitário de Volta Redonda, UniFOA.

2 Graduado em Engenharia de Produção, Centro Universitário de Volta Redonda, UniFOA.

\section{Resumo}

A água é um recurso finito que representa a fonte principal de manutenção da vida. Partilhando dessa concepção e reconhecendo a importância da preservação ambiental, aliada ao desenvolvimento econômico e social das organizações, que devem ser a cerne na atuação de um profissional de Engenharia de Produção, o presente trabalho teve como objetivo analisar as perdas de água no sistema de abastecimento de uma empresa situada na região sul do Estado do Rio de Janeiro, que possui como ativ idade secundária a distribuição de água potável. 0 objeto de estudo foi uma das quatro vilas, onde os funcionários da empresa residem. Para alcançar os objetivos propostos, a pesquisa utilizou os dados referentes à distribuição de água e, ainda, baseouse em outros estudos sobre a determinação dos indicadores de perdas. Os resultados evidenciam um alto índice de perdas, relacionado à deficiência operacional, bem como ausência de um setor específico que trabalhe na redução das perdas no sistema de distribuição. Com o objetivo de propor melhorias para os problemas encontrados, este trabalho utilizou o ciclo PDCA, em conjunto com algumas ferramentas de qualidade.

\section{Palavras-chave}

Abastecimento de água; ciclo PDCA; perda de água.

\begin{abstract}
Water is a finite resource that is the main source for maintaining life. Sharing this view and recognizing the importance of environmental conservation combined with economic and social development organizations, which should be the core of the work of a Production Engineering professional, this study aimed to analyze the water losses in the supply system a company located in the southern region of the State of Rio de Janeiro, which has as a secondary activity the distribution of potable water. The object of study was one of four villages where the employees reside. To achieve the proposed objectives, the research used data relating to the distribution of water, and also relied on other studies on loss indicators determination. The results show a high rate of loss related to operational weakness and the lack of a specific sector working in reducing loss in the distribution system. With the aim of proposing improvements to the problems encountered, this study used the PDCA cycle together with some quality tools.
\end{abstract}

\section{Keywords}

Water supply; PDCA cycle; water loss.

\section{Como você deve citar?}

LIMA, Byanca Porto de. Melhoria contínua aplicada ao processo de abastecimento de água potável. Cadernos UniFOA, Volta Redonda, n. 30, p. 23-35, abr., 2015. 


\section{INTRODUÇÃO}

Deve-se utilizar a água de forma consciente, pois é um recurso finito. Dessa forma, é preciso que a extração da água não seja superior a sua extração natural, para preservar a não escassez da fonte e garantir que a população possa ter esse recurso por longo prazo, ou seja, que haja o fornecimento de água potável para futuras gerações.

Para que a água potável chegue às residências com qualidade para consumo humano, existe o sistema de abastecimento de água, definido pela Portaria n² 2914/2011, onde se lê: "instalação composta por um conjunto de obras civis, materiais e equipamentos, desde a zona de captação até as ligações prediais, destinada à produção e ao fornecimento coletivo de água potável, por meio de distribuição" (BRASIL, 2011).

Estudos realizados no ano de 2002 pela International Water Association (IWA), concluíram que as perdas em sistemas de abastecimento de água tornaram-se, neste século, a principal preocupação das companhias de saneamento a nível mundial (GIROL, 2008).

A partir desse contexto, foi realizado um estudo para a aplicação do ciclo PDCA, na melhoria contínua do processo de abastecimento de água potável de uma empresa situada no Sul do Estado do Rio de Janeiro, delimitado a uma das vilas onde residem os funcionários da empresa estudada.

\section{SISTEMA DE ABASTECIMENTO DE ÁGUA POTÁVEL}

A sequência mais comum de um sistema de abastecimento de água potável é composta por captação de um manancial; estação elevatória, seguida das adutoras brutas; o tratamento de água em si, seguido, por sua vez, das adutoras com a água tratada, chegando, assim, aos reservatórios; a distribuição e, por fım, disponibilização nas residências. Segundo Tsutiya (2006), o objetivo principal do sistema de abastecimento de água é fornecer, ao usuário, água de boa qualidade para seu uso, em quantidade adequada e pressão suficiente.

A primeira etapa do tratamento da água inicia-se pela captação da água bruta por meio de mananciais, que, geralmente, são fontes de água doce. Os mananciais podem ser superficiais, definidos como os que escoam ou acumulam-se na superfície, tais como rios, lagos, represas e córregos; ou ainda, mananciais subterrâneos, que são aqueles encontrados nas camadas profundas do subsolo. Em ambos os tipos, o manancial deve seguir as diretrizes da legislação específica para o uso da água, de acordo com seu padrão de qualidade (SIRHSC, 2013).

Após ser captada, a água é transportada através de adutoras de água bruta, ou seja, através de canalizações que transportam a água sem tratamento para a Estação de Tratamento de Água (ETA), onde são realizados procedimentos para que a água bruta captada dos mananciais esteja, após o tratamento, em conformidade com o padrão de qualidade para o consumo humano. Após a água ser tratada, é transportada pelas adutoras de água tratada, chegando assim aos reservatórios, que são unidades que armazenam a água, para, em seguida, ir para a fase de distribuição, onde será entregue para os pontos de consumos, como: residências, indústrias, prédios etc. (COSTA, 1998). 


\section{CONTROLE E REDUÇÃO DE PERDAS}

Para Gonçalves e Alvim (2007), sistemas de abastecimento de água geralmente apresentam perdas entre a captação e a estação de tratamento de água, chamadas perdas na produção, e, desta até a entrega para o consumidor, denominadas perdas na distribuição.

Quando se pensa em perda, as primeiras imagens que vêm à mente são os vazamentos, porém o conceito de "perdas" vai, além disso. Dessa forma, torna-se necessário o reconhecimento dos tipos de perdas para a utilização das ferramentas adequadas para o controle. Portanto podem-se identificar dois tipos de perdas: a perda real e a perda aparente (GONÇALVES; ALVIM, 2007).

Segundo Tsutiya (2006), a perda física ou real corresponde à vazão de água produzida que não chega ao consumidor, caracterizada por um vazamento.

A perda por vazamento ocorre na estrutura da estação de tratamento, no rompimento das tubulações das linhas de adução e também nas redes de distribuição. De acordo com Girol (apud Lambert, 2000), esses vazamentos podem ser classificados em visíveis e não visíveis:

- Visíveis $\rightarrow$ são os vazamentos indicados pela própria população ou por técnicos das companhias de abastecimento de água que fazem as inspeções de rotina.

- Não visíveis $\rightarrow$ são os vazamentos que não afloram à superfície, ou seja, exigem o uso de equipamentos para detectá-los, tais como: geofone eletrônico e sensores de ruído, de acordo com ENOPS Engenharia (2012). Existem, ainda, vazamentos não visíveis que não afloram e não podem ser detectados, classificados como inerentes.

Segundo Tsutiya (2006), existem dois pontos importantes sobre a perda real que merecem ser destacados, que são:

- A conservação dos recursos naturais $\rightarrow$ se o volume de água perdido for baixo, não haverá necessidade de explorar os mananciais. Com isso, se reduz o impacto ambiental;

- Em relação à saúde da população $\rightarrow$ se houver tubulações com vazamentos, pode ocorrer a entrada de micro-organismos, contaminando a água, e, com isso, provocar doenças na sociedade.

As perdas aparentes são caracterizadas por não serem físicas, ou seja, não existe um vazamento real, mas existe perda comercial, que é definida pelo volume de água utilizado, mas que não é contabilizado (GIROL, 2008). As perdas aparentes ocorrem na macromedição e/ou micromedição e, ainda, na gestão comercial ineficaz:

- Macromedição $\rightarrow$ refere-se aos aparelhos utilizados para medir a vazão e pressão no sistema de abastecimento de água, ou seja, captação até antes do ponto final de entrega aos consumidores. Esses aparelhos apresentam erro de leitura e, de acordo com Girol (apud Tardelli Filho, 2006), ocorrem devido à instalação inadequada, descalibração do medidor, etc.

- Micromedição $\rightarrow$ refere-se aos aparelhos utilizados para medição, tais como hidrômetros, que são instalados na entrada do imóvel (residencial, comercial, etc.). Segundo Girol (apud Tardelli Filho, 2006), apresentam erros de leitura em decorrência de diversos fatores como: 
inclinação dos hidrômetros, envelhecimento, falta de manutenção, qualidade da água distribuída, mão de obra não qualificada etc.

- Gestão Comercial $\rightarrow$ refere-se ao registro dos consumidores. Apresenta erro, quando não há cadastramento de novas ligações, quando ligações são reativadas sem o conhecimento da companhia (ligações clandestinas), fraudes etc.

\subsubsection{Avaliação e Indicador de perda}

Avaliam-se as perdas, em geral, medindo-se a vazão e/ou volume no ponto inicial de uma etapa e medindo-se outra vez a vazão no ponto final dessa etapa. Desse modo, obtém-se a diferença que irá caracterizar a perda. Entretanto, essa medição não distingue perda real de perda aparente, sendo, portanto, o valor da perda total (GIROL, 2008).

A análise das perdas pode ser feita por meio de indicadores, que comparam os volumes perdidos, pois direciona qual ação de controle deve ser tomada. Desse modo, podemos concluir que a análise dos volumes facilita o estudo das perdas (GIROL, 2008).

O índice de perdas é outra ferramenta que pode ser utilizada para analisar as perdas totais. É o mais utilizado por se tratar de uma fórmula simples, mas que, no entanto, pode avaliar o sistema por completo ou apenas uma parte do processo (TSUTIYA, 2006).

Esse índice é calculado através da fórmula:

$I P=\frac{\text { Volume Perdido Total }}{\text { Volume Total Produzido }} \times 100(\%)$

Sendo:

$I P=$ Índice de Perdas

Volume Perdido Total $=$ Perdas Reais + Perdas Aparentes

Volume Total Produzido = Volume Fornecido

Com base no resultado obtido pela fórmula de índice de perdas, o sistema de abastecimento de água é classificado em três campos de qualificação, conforme abaixo: (TSUTIYA, 2006).

- Índice Total de Perdas menor que 25\%: Classificação do sistema como BOM.

- Índice Total de Perdas entre $25 \%$ e $40 \%$ : Classificação do sistema como REGULAR.

- Índice Total de Perdas maior que 25\%: Classificação do sistema como RUIM.

\section{ESTUDO DE CASO}

A empresa estudada está localizada no Sul do Estado do Rio de Janeiro. Sua principal atividade é a produção de energia elétrica, mas a empresa realiza, ainda, outras atividades secundárias, como o abastecimento de água potável para vilas residenciais. De acordo com Pithon (2012), dentre as vilas que a empresa distribui água, a estudada possui aproximadamente 1.800 habitantes, sendo estes os trabalhadores da empresa e seus familiares. A empresa atende, hoje, um total de 540 residências. 
Além das residências, a vila possui ainda hospital, estabelecimentos comerciais, educacionais e de lazer e, por estar localizada no litoral, recebe periodicamente um número elevado de visitantes.

De acordo com dados coletados pela empresa no ano de 2012, através da folha de leitura diária da estação de tratamento de água, consta que o volume inicial refere-se ao volume de água que sai do reservatório é, em média, aproximadamente, $50.000 \mathrm{~m}^{3}$. E o volume final, medido nas residências por meio dos hidrômetros, é, em média, de $15.000 \mathrm{~m}^{3}$.

O volume inicial não é o mesmo que o captado, pois, no ano de 2012, ainda não havia sido instalado um medidor de vazão na captação, sendo, assim, impossível avaliar o sistema como um todo.

\subsection{Aplicação do PDCA na Melhoria do Processo de Distribuição de Água}

Diante do atual cenário apresentado, a proposta do projeto é realizar a melhoria contínua no processo de distribuição de água potável, através da aplicação da etapa "P" do ciclo PDCA (Figura 1).

Figura 1 - Ciclo PDCA

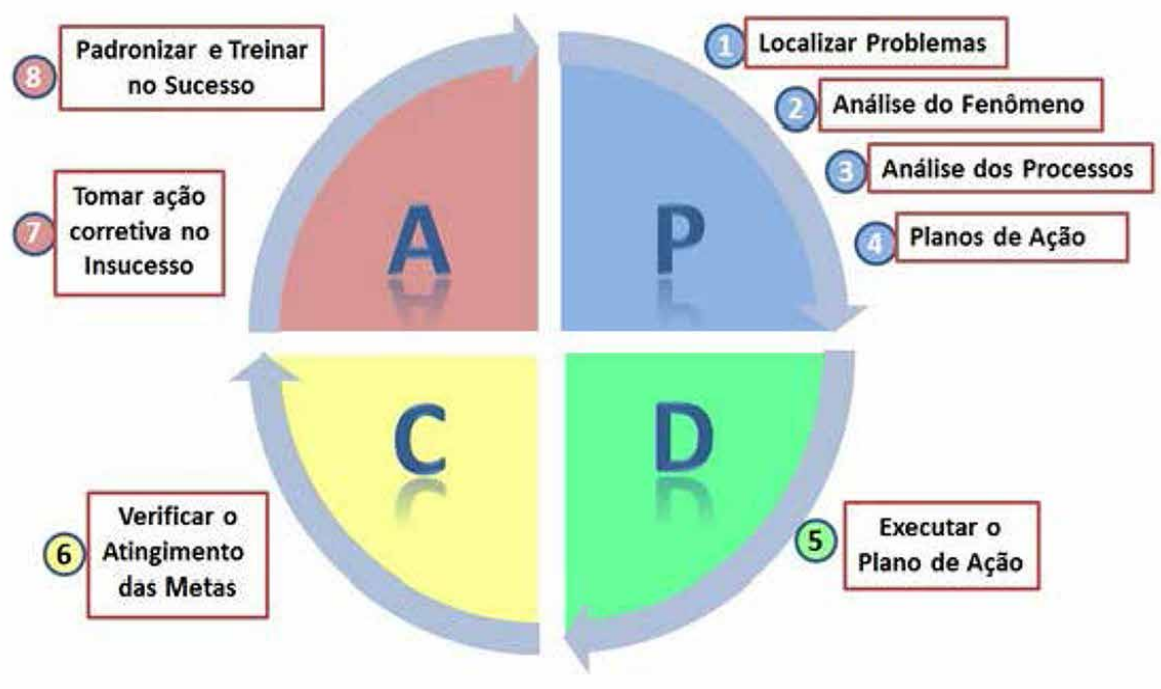

Fonte: SLACK (2009)

De acordo com Coelho (2009), para alcançar o objetivo de redução de perdas e criar um plano de ação para controle, é necessário responder a três perguntas básicas: "Onde perdemos?"; "Quanto perdemos?" e "Por que perdemos?"

Baseado nessas considerações, trabalhou-se nas seguintes etapas: descrição do processo para a identificação do problema (ONDE); mensuração dos volumes perdidos; índice de perdas (QUANTO) e gestão da empresa, motivos que levam às perdas (POR QUE).

Para compreensão do processo de distribuição de água potável, foi confeccionado um desenho esquemático, conforme figura 2. 
Figura 2 - Esquema do Processo

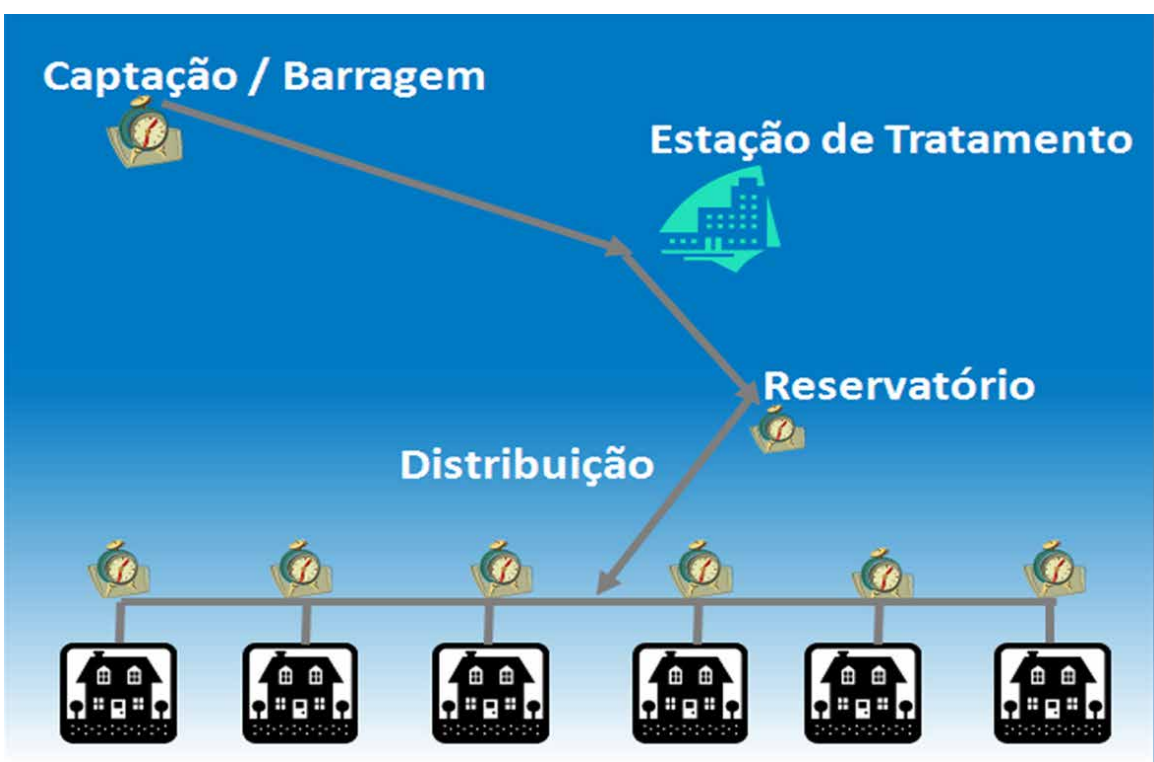

Fonte: dos autores.

O volume inicial não é o mesmo que o captado, pelo fato de não existir um medidor de vazão na captação. Logo, o volume inicial refere-se ao volume de água que sai do reservatório. Dessa forma, para se descobrir e calcular quanto é a ocorrência de perdas de água na etapa de distribuição, é necessário realizar a subtração do volume medido na saída do reservatório de água tratada, pelo volume total medido por meio dos hidrômetros instalados na entrada de cada imóvel, seja ele residencial ou comercial (Quadro1).

Quadro 1- Perdas em $\mathrm{m}^{3}$ da água distribuída na vila de estudo

\begin{tabular}{|c|c|c|c|}
\hline \multirow{2}{*}{ Mês (2012) } & \multicolumn{2}{|c|}{ Volume Medido $\left(\mathbf{m}^{\mathbf{3}}\right)$} & \multirow{2}{*}{ Perda $\left(\mathbf{m}^{\mathbf{3}}\right)$} \\
\cline { 2 - 4 } & Reservatório & Distribuição & 30.486 \\
\hline Janeiro & 50.020 & 19.534 & 36.055 \\
\hline Fevereiro & 49.030 & 12.975 & 37.265 \\
\hline Março & 51.050 & 13.785 & 33.500 \\
\hline Abril & 49.120 & 15.620 & 35.507 \\
\hline Maio & 50.450 & 14.943 & 35.338 \\
\hline Junho & 47.880 & 12.542 & 34.298 \\
\hline Julho & 48.830 & 14.532 & 36.928 \\
\hline Agosto & 51.940 & 15.012 & 40.839 \\
\hline Setembro & 49.990 & 9.151 & 35.689 \\
\hline Outubro & 51.460 & 15.771 & 39.583 \\
\hline Novembro & 49.410 & 9.827 & 28.562 \\
\hline Dezembro & 49.370 & 20.808 & $\mathbf{4 2 4 . 0 5 0}$ \\
\hline
\end{tabular}

Fonte: Os Autores 
Diante do elevado volume de perdas e por não conseguir distingui-las, devem ser levadas em consideração as perdas totais, ou seja, perdas reais e perdas aparentes (GIROL, 2008). Entretanto, por não haver conhecimento do percentual que a perda representa no mês, faz-se necessário um estudo aprofundado para distinguir qual seu percentual de desperdício na fase de distribuição. Esse estudo pode ser baseado no percentual das perdas, que é conhecido através da fórmula de índice de perdas.

Foi utilizada a fórmula de índice de perdas (Quadro 2), que identifica o percentual de perdas de cada mês. Depois de analisar os valores obtidos pela referida fórmula, observa-se que, em todos os meses, os percentuais estão acima de $50 \%$. O percentual anual é de $71 \%$.

Quadro 2 - Percentual de Perdas na Distribuição $\left(\mathrm{m}^{3}\right)$

\begin{tabular}{|c|c|c|c|}
\hline \multicolumn{4}{|c|}{ Percentual de Perda de Água na Distribuição (\%) } \\
\hline MÊS (2012) & Volume Perdido & Volume Fornecido & Índice de Perdas \\
\hline Janeiro & 30.486 & 50.020 & $60,95 \%$ \\
\hline Fevereiro & 36.055 & 49.030 & $73,54 \%$ \\
\hline Março & 37.265 & 51.050 & $73,00 \%$ \\
\hline Abril & 33.500 & 49.120 & $68,20 \%$ \\
\hline Maio & 35.507 & 50.450 & $70,38 \%$ \\
\hline Junho & 35.338 & 47.880 & $73,81 \%$ \\
\hline Julho & 34.298 & 48.830 & $70,24 \%$ \\
\hline Agosto & 36.928 & 51.940 & $71,10 \%$ \\
\hline Setembro & 40.839 & 49.990 & $81,69 \%$ \\
\hline Outubro & 35.689 & 51.460 & $69,35 \%$ \\
\hline Novembro & 39.583 & 49.410 & $80,11 \%$ \\
\hline Dezembro & 28.562 & 49.370 & $57,85 \%$ \\
\hline MÉDIA & $\mathbf{3 5 . 3 3 8}$ & $\mathbf{4 9 . 8 7 9}$ & $\mathbf{7 1 , 0 0 \%}$ \\
\hline TOTAL & $\mathbf{4 2 4 . 0 5 0}$ & $\mathbf{5 9 8 . 5 5 0}$ & $\mathbf{7 1 , 0 0 \%}$ \\
\hline & & & \\
\hline & & & \\
\hline
\end{tabular}

Fonte: Os Autores

Segundo a publicação da Repórter da Agência Brasil, Gandra (2011), o coordenador do Sistema Nacional de Informações sobre o Saneamento (SNIS), Ernani Ciríaco de Miranda, relata que o Brasil trabalhou num nível de $37 \%$ a $42 \%$ de perda nos últimos anos, porém, segundo ele, esse fato é bom, pois mostra que, apesar de ser um percentual alto, está estabilizado. Miranda ainda estimou que uma média de perda aceitável para o Brasil seria 25\%. Para chegar a esse nível, deve-se melhorar o sistema de distribuição à população, pois, para Miranda, a perda na distribuição indica que não é dada a devida importância nessa etapa.

Diante dessa afirmativa e dos resultados terem apresentado índices de perdas tão elevados, neste estudo de caso, fica comprovado à necessidade de implantar um controle rígido na fase de distribuição do processo, a fim de que esse número esteja dentro do aceitável.

Baseando-se na classificação das perdas, as quais podem ser categorizadas em bom (menor do que $25 \%$ ), regular ( $25 \%$ - $40 \%$ ) ou ruim (maior do que $40 \%$ ), o processo da empresa enquadra-se como ruim, pois todos os índices de perdas são superiores a $40 \%$. 
Os problemas enfrentados pela empresa na realização de sua atividade secundária, nos dias de hoje, foram identificados como perdas na etapa de distribuição e com um grau relativamente alto, de acordo com o cálculo do percentual. Atualmente, não existe nenhuma gestão para detectar as causas, logo, nenhuma gestão para a redução das perdas.

A seguir, para análise inicial do problema, será apresentado como a empresa faz atualmente sua gestão, ou seja, a gestão das macromedições, micromedições etc.

\subsubsection{Perdas Aparentes}

1. Gestão Comercial: Não existe um programa de cadastramento comercial, ou seja, pode haver residências sem moradores, assim como residências com novos moradores. Não é feito o cancelamento do fornecimento de água para residências desabitadas e não existe um profissional responsável por esse serviço.

2. Gestão das Macromedições: Através de pesquisa de campo, foi observada a inexistência de medidor de vazão na captação de água, no ano de 2012. Porém, no ano de 2013, foi verificada a primeira instalação desse medidor. Dessa forma, não é realizada medição na captação de água. Não há inspeção nem tampouco manutenção preventiva, apenas manutenção corretiva.

3. Gestão das Micromedições: Os dados obtidos durante a pesquisa de campo mostraram que os hidrômetros foram instalados nas residências e no centro comercial há cerca de 10 anos, e, desde então, não foram realizadas trocas. Também não existem inspeções de rotina para constatar possíveis falhas, nem um plano de manutenção preventiva. Logo, são realizadas apenas manutenções corretivas. Observou-se, ainda, que, no mês de janeiro de 2012, foram realizadas as primeiras leituras dos hidrômetros. Não existe um funcionário qualificado para o serviço.

\subsubsection{Perdas Reais}

1. Gestão dos Vazamentos Visíveis: Assim como ocorre, nas perdas aparentes, a gestão dos vazamentos visíveis não possui manutenção preventiva, não existindo monitoramento com o intuito de identificar vazamentos. Só é feito a manutenção corretiva, quando a água aflora a superfície.

2. Gestão dos Vazamentos não Visíveis: A empresa não possui equipamentos para detectar os vazamentos não visíveis. Dessa forma, esses vazamentos só são encontrados quando atingem a superfície.

\subsection{Aplicação da Ferramenta de Qualidade}

Com base na análise da gestão de distribuição de água da empresa, juntamente com dados da revisão teórica, foi utilizada a ferramenta de qualidade, diagrama de causa e efeito, conhecido como espinha de peixe ou ishikawa, para descobrir quais as possíveis causas fundamentais do problema identificado (SLACK; 2009). 
Figura 3 - Diagrama de Causa e Efeito

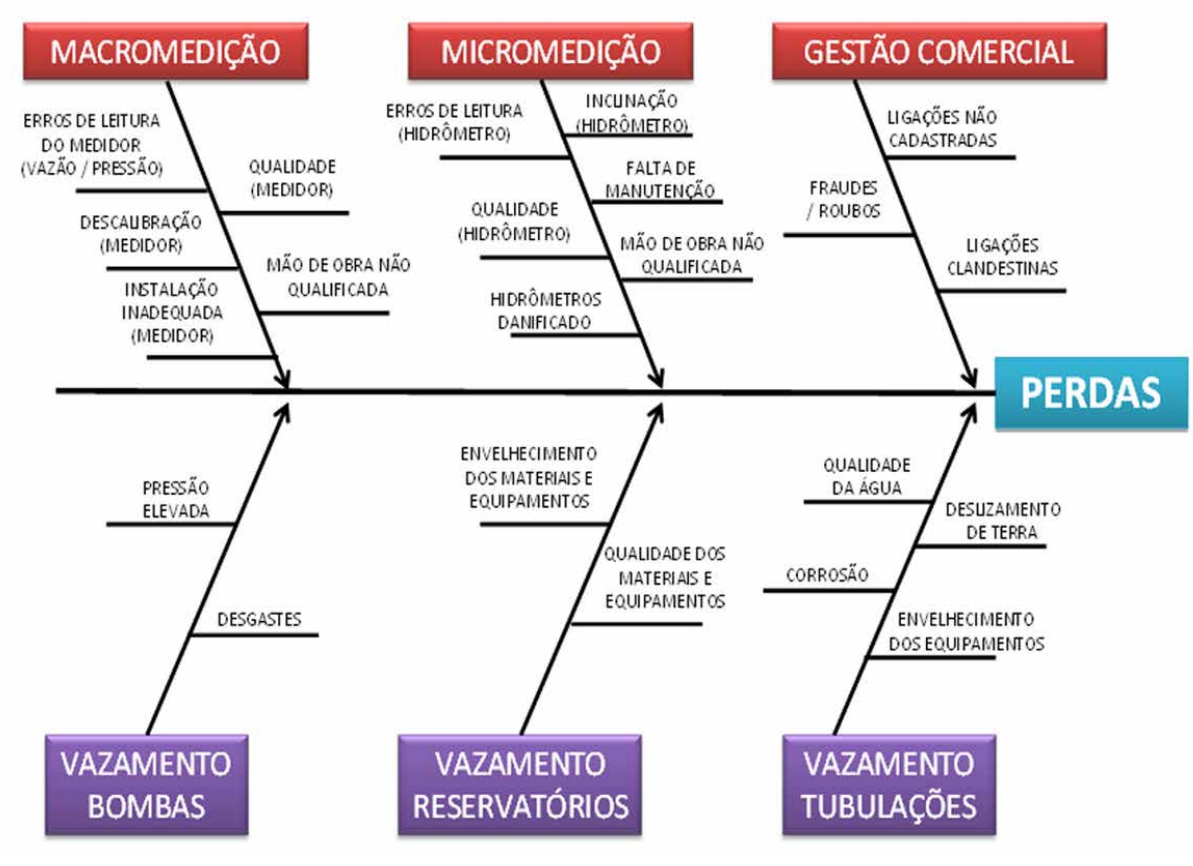

Fonte: Os Autores

De acordo com Girol (apud Araújo, 2005), as perdas totais de um sistema de abastecimento de água estão distribuídas da seguinte forma: $60 \%$ de perda aparente e $40 \%$ de perda real.

Feito um comparativo dessa informação com a situação atual da empresa, foi verificado que, no ano de 2012 , a perda total representou em torno de $424.050 \mathrm{~m}^{3}$. Se esse valor corresponder a $100 \%$, logo, o equivalente a $60 \%$ das perdas totais representa $254.430 \mathrm{~m}^{3}$ de perdas aparentes, e, por fim, $40 \%$ das perdas totais representam $169.620 \mathrm{~m}^{3}$ de perdas reais. Isso corresponde a um índice de perda total de $71 \%$, sendo classificado como ruim.

Neste trabalho, será apresentado um plano de ação, cujo objetivo é eliminar as perdas aparentes e, com isso, reduzir o índice de perda total para $28 \%$, passando a ser classificado como um índice regular. Entretanto, as perdas continuarão a existir, mas estarão em um nível menor, representando uma melhoria significativa ao sistema.

O plano de ação que será apresentado a seguir propõe-se a solucionar todas as causas de perdas aparentes. Para isso, foi utilizada a ferramenta $5 \mathrm{~W} 1 \mathrm{H}$, muito utilizada para realização de bons planejamentos. 0 nome dessa ferramenta designa uma sigla em inglês, sendo: what (o que), who (quem), when (quando), where (onde), why (por que) e how (como). (TOLEDO et al; 2013)

Segundo Tsutiya (2006), um plano de ação pode ser definido como aquele que busca combater os efeitos ou as causas de determinado problema. Nele, estão incluídos quatro componentes que constituem a base para o gerenciamento das perdas aparentes: (1) qualificação da mão de obra (2); redução de erros de medidores; (3) redução de fraudes e (4) melhorias no sistema comercial. 


\subsubsection{Qualificação da Mão de Obra}

A falta de profissionais qualificados pode acarretar em uma instalação inadequada de medidores, o que ocasiona, consequentemente, sua descalibração e/ou inclinação, situações estas que geram erros de leitura. A presença de um funcionário qualificado propicia maior chance de identificação prematura dos equipamentos que necessitam de manutenção, podendo ainda, prevenir situações com potencial de agravamento.

De acordo com essa necessidade, montou-se um plano de ação que foi dividido em duas etapas (Quadro 3), com o intuito promover a inserção de novos colaboradores treinados ou a realização do treinamento dos profissionais que, atualmente, ocupam os cargos.

\subsubsection{Redução de Erros dos Medidores}

De acordo com TSUTIYA (2006), a redução de erros dos medidores possui ações bastante significativas, tais como: a especificação correta dos medidores, a instalação adequada dos medidores e hidrômetros, a troca corretiva e preventiva de hidrômetros e a calibração periódica de medidores.

Nesse contexto, torna-se de extrema relevância a especificação correta dos medidores, bem como sua instalação adequada, respeitando as particularidades de cada equipamento. Com isso, um estudo do material mais apropriado para cada localidade deve ser realizado previamente, garantindo a instalação adequada, promovendo assim maior durabilidade. No quadro 4, são expressas as ações a serem tomadas para alcançar tais objetivos.

No que se refere à manutenção preventiva e corretiva dos medidores, torna-se indispensável que exista uma calibração periódica dos medidores. Essa afirmação baseia-se no fato de que todos os equipamentos possuem vida útil. No caso específico dos hidrômetros, estudos apontam que os mesmos têm, aproximadamente, 5 a 10 anos. Como relatado por Tsutiya (2006), os erros nos equipamentos de medições são ocasionados devido à falta de manutenção preventiva, o que impede que tenham uma boa precisão e sejam conservados. Desse modo, propôs-se um plano de ação para ações preventivas e corretivas (Quadro 4).

\subsubsection{Redução de Fraudes}

Segundo Tsutiya (2006), o componente de redução de fraudes envolve as ações de inspeção de ligações com suspeita de interferência na contabilização do consumo de água e medidas de coibição dessa prática. Nesse aspecto, torna-se importante enfatizar que a fraude é crime, passível de todos os procedimentos jurídicos e processuais usuais para o enquadramento nas penalizações previstas em lei.

Para evitar a ocorrência de fraudes, é proposta uma equipe de investigação que irá inspecionar os locais de quinze em quinze dias. Outra maneira de diminuir casos fraudulentos seria envolver os hidrômetros com caixas com cadeados, para, assim, limitar o acesso de pessoas leigas. (Quadro 4)

\subsubsection{Melhorias no Sistema Comercial}

Para Tsutiya (2006), as melhorias no cadastro comercial estão relacionadas ao aperfeiçoamento contínuo do sistema de gestão comercial da companhia, especialmente no que diz respeito ao cadastramento das ligações e apuração dos consumos dos clientes. 
A gestão de todas as atividades comerciais da companhia exige sistemas de informação e controles adequados, podendo variar de acordo com o tamanho e complexidade, em função do porte da área em questão. Tais sistemas envolvem o acatamento do pedido de ligação do cliente, cadastramento comercial da ligação após sua execução, programação das leituras, apuração do consumo (leitura), emissão de contas e geração de relatórios gerenciais.

A melhora do sistema comercial eliminará as ligações não cadastradas, a fim de otimizar o sistema com boa tecnologia, o que auxiliará o trabalho dos funcionários e a precisão dos dados estatísticos. 0 plano de ação para esse componente é apresentado no quadro 4.

Deve ser dada atenção especial à agilidade do cadastramento das novas ligações de água no sistema comercial, bem como de todas as atividades, visando descobrir falhas no cadastro, de modo a eliminar as ligações não cadastradas, ligações clandestinas ou ligações suprimidas do cadastro.

A proposta para melhorar o sistema comercial é o desenvolvimento de um software capaz de tornar ágil o cadastramento, ou seja, automatizando esse processo. Com isso, será mais fácil a visualização das ligações existentes e aquelas que serão desligadas, de outras que não necessitam, por ter abastecimento próprio.

Quadro 3 - Proposta de Qualificação de Mão de Obra (2a etapa)

\begin{tabular}{|c|c|}
\hline \multicolumn{2}{|r|}{1 - Qualificação da Mão-de-obra } \\
\hline \multicolumn{2}{|r|}{$1^{\text {a }}$ ETAPA } \\
\hline What? & Definição dos cargos (quantidade e perfil) \\
\hline Why? & Para adquirir um quadro de funcionários competentes. \\
\hline Where? & Setores de cadastro, compras, medições, qualidade, instalação e manutenção. \\
\hline Who? & Chefe de Divisão (área responsável pelo abastecimento). \\
\hline When ? & O mais rápido possível, até completar o quadro. \\
\hline How ? & $\begin{array}{l}\text { Chefe de Divisão fará uma pesquisa para ver vagas em aberto e qual será o treinamento necessário para cada } \\
\text { função. }\end{array}$ \\
\hline \multicolumn{2}{|r|}{$2^{\text {a }}$ ETAPA } \\
\hline What? & Admissão de funcionários qualificados. \\
\hline Why? & Para adquirir um quadro de funcionários competentes. \\
\hline Where? & Setores de cadastro, compras, medições, qualidade, instalação e manutenção. \\
\hline Who? & Consultoria de RH. \\
\hline When ? & O mais rápido possível, até completar o quadro. \\
\hline How ? & $\begin{array}{l}\text { A consultoria de RH fará a seleção de currículos, entrevistas, admitindo o funcionário que melhor se adéqua } \\
\text { à função. Além de proporcionar o treinamento dos funcionários que ocupam atualmente os cargos e os que } \\
\text { serão contratados. }\end{array}$ \\
\hline
\end{tabular}




\subsubsection{Redução de Erros dos Medidores}

\section{Quadro 4 - Melhoria no Sistema Comercial}

\begin{tabular}{|c|c|}
\hline \multicolumn{2}{|r|}{2 - Redução de Erros dos Medidores } \\
\hline \multicolumn{2}{|r|}{ Ação 01} \\
\hline What? & Especificação e instalação adequada. \\
\hline Why? & Para obtenção de produtos bons e adequados. \\
\hline Where? & Em todos os equipamentos (medidores / hidrômetros). \\
\hline Who? & Técnico em manutenção e auxiliar de compras. \\
\hline When? & Sempre que for necessário comprar. \\
\hline How? & $\begin{array}{l}\text { Será feito um estudo pelo técnico, para analisar o local que será instalado, bem como a vazão que passará e } \\
\text { o aparelho que melhor se adéqua às especificações. A auxiliar de compras será responsável em comprar o } \\
\text { equipamento que esteja dentro das especificações pedidas pelo técnico. }\end{array}$ \\
\hline \multicolumn{2}{|r|}{ Ação 02} \\
\hline What? & Estabelecer Plano de Manutenção preventiva, corretiva e calibração dos medidores. \\
\hline Why? & Para obter dados mais precisos. \\
\hline Where? & Em todos os equipamentos (medidores / hidrômetros). \\
\hline Who? & Técnico em manutenção e leiturista. \\
\hline When? & Uma semana \\
\hline How? & $\begin{array}{l}\text { A manutenção preventiva deverá ser feita pelo técnico, porém o leiturista deve anotar a data da primeira } \\
\text { manutenção, para que o técnico saiba quando deverá ser a próxima manutenção. }\end{array}$ \\
\hline \multicolumn{2}{|r|}{3 - Redução de Fraudes } \\
\hline What? & Investigação nos equipamentos (medidores / hidrômetros). \\
\hline Why? & Para constatar possíveis fraudes e roubos. \\
\hline Where? & Em todos os equipamentos (medidores / hidrômetros). \\
\hline Who? & Auxiliar de apontamento. \\
\hline When? & Quinzenalmente. \\
\hline How? & $\begin{array}{l}\text { Inspeção visual a fim de identificar possíveis ligações suspeitas de interferência, e proteção aos } \\
\text { equipamentos, através de caixas com cadeados, de forma a limitar o acesso de pessoas leigas. }\end{array}$ \\
\hline \multicolumn{2}{|r|}{4 - Melhoria no Sistema Comercial } \\
\hline What? & Cadastramento de moradores \\
\hline Why? & Para saber o número de consumidores \\
\hline Where? & $\mathrm{Na}$ vila residencial \\
\hline Who? & Programador \\
\hline When? & Mensalmente \\
\hline How? & Software de cadastro \\
\hline
\end{tabular}

Fonte: Os autores 


\section{CONCLUSÃO}

Com o trabalho foi possível constatar que existem perdas de água significativas no processo de distribuição de água potável da empresa situada no litoral sul do Estado do Rio de Janeiro, que não são levadas em consideração por não ser a atividade prioritária da empresa, mas que, no entanto, tendo em vista a necessidade de implementação de ações sustentáveis para as organizações dos mais distintos segmentos, representam uma necessidade urgente.

O trabalho propôs a redução de perdas de água de $71 \%$ para $28 \%$ com o uso de ferramentas da qualidade e apoiado ao Ciclo PDCA, a fim de fazer com que o sistema saia da situação ruim e fique, pelo menos, na regular, de acordo com o exposto por Tsutiya (2006).

Verifica-se a possibilidade de minimizar as perdas de água, sem que isso represente grandes custos à empresa, o que pode ser alcançado por meio da admissão de novos funcionários ou promoção dos já existentes, melhoria da gestão comercial, introdução da manutenção preventiva, entre outras ações. Em médio e longo prazo outras ações como, aperfeiçoamento dos aparelhos de medição e mudanças na instalação dos hidrômetros poderão promover mais avanços.

\section{REFERÊNCIAS BIBLIOGRÁFICAS}

BRASIL. Ministério da Saúde. Portaria ${ }^{\circ}$ 2914, de 12 de dezembro de 2011. Dispõe sobre os procedimentos de controle e vigilância da qualidade da água para consumo humano e seu padrão de potabilidade.

COSTA, Cesar Bassi. Desenvolvimento de Estrutura de Custo para Análise de Viabilidade Técnica e Econômica - Financeira de Sistemas de Abastecimento de Água. 1998. Dissertação (mestrado) Universidade Sul Fluminense. Niterói, 1998.

ENOPS Engenharia. Pesquisa de Vazamentos. Disponível em: <http://www.enops.com.br/site/index. php?/ENOPS-Engenharia/Pesquisa-de-Vazamento/>. Acesso em: 10 jan. 2013.

GANDRA, Alana. Índice de Perda de Água Tratada no Brasil éElevado, 2011. Disponível em: <http://agenciabrasil. ebc.com.br/noticia/2011-09-11/indice-de-perda-de-agua-tratada-no-brasil-e-elevado>. Acesso em: 7 abr. 2013.

GIROL, Guilherme Violato. Análise de Perdas Reais em um Setor do Sistema de Abastecimento de Água no Município de Capinzal - SC. 2008. 62 f. Monografia - Curso de Graduação em Engenharia Sanitária e Ambiental. Universidade Federal de Santa Catarina. Florianópolis, SC. 2008.

GONÇALVES, Elton; ALVIM, Paulo Roberto Ambrósio. Pesquisa e Combate a Vazamentos não Visíveis. Guias práticos: técnicas de operação em sistemas de Abastecimento de água. Volume 3. Brasília: SNSA, 2007. 87 p.

PITHON, Barbara. Relatório Técnico - Solicitação de Outorga de Direito de Uso de Recurso Hídrico Captação de Água Doce na União dos Córregos 1 e 2 da Bacia de Praia Brava. Rio de Janeiro, 2012. 6 p.

SLACK, N; CHAMBERS, S; JOHNSTON, R. Administração da produção. 3. ed. São Paulo: Atlas, 2009.

TOLEDO, J. et al. Qualidade: gestão e métodos. Rio de Janeiro: LTC, 2013.

TSUTIYA, Milton Tomoyuko. Abastecimento de água. 4. ed. São Paulo: Departamento de Engenharia Hidráulica da Escola Politécnica da Universidade, 2006. 643 p. 